\title{
Qualitative Assay of Synovial MAGE-1 m-RNA as a New Trend in Diagnosis of Rheumatoid Arthritis
}

\author{
Eman Abd Elkader Abd Elsalam, Ibrahim El-Maghawry, \\ Nader M.M.A., Ahmad Emerah * \\ Medical Biochemistry and Rheumatology \& Rehabilitation* \\ Departments, Faculty of Medicine, Zagazig University
}

\begin{abstract}
Rheumatoid Arthritis (RA) is the commonest inflammatory joint disease, affecting nearly $1 \%$ of the adult population worldwide. Its diagnosis depends on clinical symptoms, laboratory investigations and imaging. The emphasis in the management of this disease is early diagnosis and intervention. Diagnostic specificity of rheumatoid factor (RF) for RA is poor since it is also found in many other rheumatic and non-rheumatic diseases. Anticyclic citrullinated peptide (anti-CCP) was reported to have a high specificity for RA diagnosis, especially in patients with early disease. However, it was found to have lower sensitivity than RF in RA diagnosis. This study aimed to evaluate the expression of MAGE-1 mRNA by the synovial fluid cells from inflamed joints, and the serum levels of anti-CCP as biochemical markers for the early diagnosis of RA. The study included 30 subjects of both sexes: 10 controls with traumatic knee joint effusion and 20 rheumatoid arthritis patients. Both Serum RF and anti-CCP were determined quantitatively by enzyme-linked immune-sorbent assay (ELISA). The expression of MAGE-1 mRNA by the synovial fluid cells obtained from the inflamed joints is evaluated by applying reverse transcription-PCR amplification. MAGE-1 mRNA was detected in synovial fluid cells of all patients but not in controls. There was significant increase $(P<0.01)$ of both serum RF IgM and anti-CCP in rheumatoid patients group when compared to control one. There was significant positive correlation $(r=0.928 ; P=<0.01)$ between serum RF IgM and anti-CCP. The specificity of MAGE-I, Anti-CCP and RF in RA diagnosis was $100 \%$, and the sensitivity of both MAGE-I and Anti-CCP was $100 \%$ while that of RF was $85 \%$. Conclusively, the expression results of MAGE-1 transcript in synovial fluid were $100 \%$ positive encouraging its utilization as a biochemical marker for RA diagnosis. The combined use of serum anti-CCP and MAGE-1 transcript in the synovial fluid cells is recommended for early diagnosis of $R A$.
\end{abstract}

\section{INTRODUCTION}

Rheumatoid arthritis (RA) is a systemic inflammatory disease with a predilection for symmetrically distributed diarthroidal joints. It is clinically heterogeneous, with particular disease phenotypes defined according to a complex interplay of genes and the environment ${ }^{(\mathbf{1})}$.

The relationship of many biomarkers with disease 
characteristics is confounded by factors unrelated to the disease, and that only few biomarkers exist with some predictive value. Moreover, clinical markers appear of equal value as biomarkers for this purpose, although they likewise have limited capacity in these regards. The analysis suggests the search for better markers to predict outcomes and therapeutic responsiveness in RA, needs to be intensified $^{(2)}$.

The presence of autoantibodies in the serum of patients is a very typical phenomenon for autoimmune disease $^{(3)}$. Although the diagnosis of RA relies primarily upon clinical symptoms, laboratory tests that detect autoantibodies, such as RF and antiCCP, are helpful aids in diagnosis. The usefulness of these autoantibodies in established RA has been demonstrated, but more researches are needed to determine the value of these tests in detection of early RA, disease prognosis, and disease monitoring ${ }^{(4)}$.

The first citrulline-binding autoantibodies in RA sera were discovered by Nienhuis and Mandema $^{(5)}$ and are able to bind to peri-nuclear granules in normal human buccal mucosa cells. They were named antiperinuclear factor that was found in $48 \%$ of patients with RA, and only $1 \%$ of healthy controls. The specificity of antiperinuclear factor for citrulline was not appreciated until years later; however, Young et al. ${ }^{(6)}$ reported that RA sera contained antibodies that reacted to the keratinized layer of epithelium. These antibodies were called antikeratin antibodies, and were only found in RA patients. Subsequent studies demonstrated that anti-keratin antibodies and antiperinuclear factor recognized a similar epitope, and were perhaps the same antibody ${ }^{(7)}$. It was also discovered that conversion of arginine to citrulline on peptides was essential for anti-keratin antibody and perinuclear factor binding ${ }^{(8)}$.

Antiperinuclear factor and antikeratin antibodies can be broadly categorized as anti-citrullinatedpeptide antibodies. There is evidence for abnormal citrullination of various peptides in a diverse array of human diseases, including rheumatoid arthritis, psoriasis, and multiple sclerosis $^{(9)}$. The formation of antibodies to citrullinated peptides seems to be specific for RA patients $^{(\mathbf{1 0})}$.

In 1991, researchers first isolated Melanoma antigen gene (MAGE)-A1 from an MZ-2 human melanoma cell line. In the following years, dozens of new MAGE gene were identified ${ }^{(\mathbf{1 1 )}}$. Based on expression patterns, the MAGEs were classified as belonging to either subgroup I or II. Members of subgroup I, including MAGE-A, -B and $-C$, are expressed in malignant tumors and testis, but not in other normal tissues. These members are named as cancer/testis antigen and tumor-specific antigen. However, subgroup II MAGEs is expressed in various normal adult human tissues $^{(12)}$.

The MAGE-B2 gene, localized to MAGE Xp-2 was isolated from an expression library using sera from pediatric patients with systemic lupus erythematosus. This finding suggests an immune response to MAGE proteins in diseases of immune dysregulation $^{(13)}$. 
Our study was designed to evaluate the expression of MAGE-1 mRNA by synovial fluid cells from inflamed joints, and the serum levels of anti-CCP as biochemical markers for the early diagnosis of RA and to try clarification of their roles in the pathogenesis of RA.

\section{SUBJECTS \& METHODS}

Thirty subjects of both sexes with age ranging from 20 to 40 years were enrolled in this study and were selected from those for follow up in the Rheumatology Department, Zagazig University Hospitals. They were categorized into two groups: Group I (Control group) comprising 10 subjects with traumatic knee joints and group II including 20 RA patients. A written informed consent was taken from each subject included in the study. All subjects were submitted to medical history taking, general and local examination to exclude any other autoimmune diseases.

Three ml blood was collected from all subjects and sera were separated and stored at $-20{ }^{\circ} \mathrm{C}$ until $\mathrm{RF}$ and anti-CCP antibodies analysis. Synovial fluids were aspirated in EDTA tubes from the knee joints of the enrolled subjects by the Rheumatologist. Synovial fluid cells were separated after centrifugation, spun down, washed by RPMI 1640 medium (Sigma, USA) and resuspended in RPMI1640 supplemented by $5 \%$ fetal bovine serum and stored in $-80^{\circ} \mathrm{C}$.

Serum RF IgM was determined quantitatively by enzyme immunoassay according to Dabadghao, et al. ${ }^{(14)} \mathrm{RF}$ IgM ELISA
Kit (Immunolab GmbH, Germany) and ELISA Reader (SLT-Spectra. Mode-III, Austria). The cut off value was $50.0 \mathrm{IU} / \mathrm{ml}$.

Serum anti-CCP antibodies were measured according to Quinn, et al. ${ }^{(15)}$ using commercially available ELISA kit (Axis-Shield, UK) and ELISA Reader (SLT-Spectra. ModeIII, Austria). The cut off value was 5.0 $\mathrm{IU} / \mathrm{ml}$.

RT-PCR:

Total RNA was extracted from isolated synovial fluid cells using E.Z.N.A. total RNA kit (Omega Biotek, USA) according to the protocol provided by the manufacturer.

Reverse transcription and PCR amplification were performed using Ready-to-Go RT-PCR Beads kit (Amersham Biosciences limited, UK) according to Noonan and Roninson $^{(16)}$. Each bead is optimized to allow first-strand cDNA synthesis and PCR reactions to proceed as a single tube; when brought to a final volume of $50 \mu \mathrm{l}$, each reaction contained $\sim 2$ units of taq DNA polymerase, $10 \mathrm{mM}$ Tris-Hcl, $60 \mathrm{mM}$ $\mathrm{Kcl}, 1.5 \mathrm{mM} \mathrm{Mgcl}, 200 \mu \mathrm{M}$ of each dNTP, M-MULV Reverse Transcriptase, RNA guard Ribonuclease inhibitor (porcine) and stabilizers including RNAse/DNAse free bovine serum albumin (BSA).

The bead was dissolved using DEPC-dd- $\mathrm{H}_{2} \mathrm{O}$, then $2.5 \mu \mathrm{g}$ RNA template and $3 \mu \mathrm{l}$ of the first strand (cDNA) primer pd $\left(\mathrm{N}_{6}\right)$ were added individually to the dissolved bead, the reactions were transferred to the thermal cycler and incubated at $42{ }^{\circ} \mathrm{C}$ for 30 minutes then at $95{ }^{\circ} \mathrm{C}$ for 5 minute then $2.5 \mu \mathrm{l}$ of each PCR 
primer was added (The sequences of MAGE-1 primers were as follows: forward-5'-CGG CCG AAG GAA CCT GAC CCA G-3' and reverse-5'GCT GGA ACC CTC ACT GGG TTG CC-3'(17). The volume of the reaction was completed with DEPCdd- $\mathrm{H}_{2} \mathrm{O}$ to give a final volume of 50 $\mu \mathrm{l}$ where it was used for dissolving the bead.

The PCR amplifications were performed by pre-programmed Thermal Cycler PTC-100 machine (USA) under the following conditions according to Mou et al. ${ }^{(17)}\left(94^{\circ} \mathrm{C}\right.$ for $45 \mathrm{~s}, 65^{\circ} \mathrm{C}$ for $45 \mathrm{~s}$ and $72^{\circ} \mathrm{C}$ for $45 \mathrm{~s}$ ) for 25 cycles.

B-actin gene was determined to assess the integrity of the RNA. The sequences of $\mathrm{B}$-actin primers were as follows: forward-5'-GGC ATC GTG ATG GAC TCC G-3' and reverse-5'GCT GGA AGG TGG ACA GCG A3'. The amplification conditions were $\left(94^{\circ} \mathrm{C}\right.$ for $45 \mathrm{~s}, 65^{\circ} \mathrm{C}$ for $45 \mathrm{~s}$ and $72^{\circ} \mathrm{C}$ for $45 \mathrm{~s}$ ) for 28 cycles $^{(17)}$.

The amplified products were run in 1.7 agarose gel using the EC 360 Submarine Gel electrophoresis system (Maxicell, EC 360 M-E-C apparatus, USA). The results were visualized by ethidium bromide staining under ultraviolet transillumination then digital camera photographing.

The sample was considered positive when a band was observed at 421 bp for MAGE-1 and also B-actin gene was determined to assess the integrity of the RNA where it gave a band at $613 \mathrm{bp}^{(\mathbf{1 7 )}}$, using a $100 \mathrm{bp}$ DNA marker.

\section{Statistical analysis:}

The results were statistically analyzed using SPSS program (version 16). The data were reported as mean \pm standard deviation (SD). Suitable statistical analysis was applied as unpaired student t-test, bivariate correlation coefficient (r), Fisher's exact test and sensitivity \& specificity tests (ROC) curve. P values less than 0.01 were considered significant.

\section{RESULTS}

In the control group, MAGE-1 mRNA could not be detected in synovial fluid of all subjects, whereas in the RA group, MAGE-1 mRNA was detected in all patients. By using Fisher's exact test (table 1), the frequency of the MAGE-1 transcript detected in synovial fluid was significantly higher in RA group than in the control one $(P \leq 0.01)$. The electrophoresis of PCR products of the synovial fluid cells were demonstrated in figure (1).

t-test, as represented in table (2), showed significant increase (P $<0.01)$ of both RF and anti-CCP in RA group when compared to the control group. There was significant positive correlation $(\mathrm{r}=0.928 ; \mathrm{P}=<$ 0.01 ) between the RF and antiCCP.

It was revealed that the specificity of each of MAGE-I, AntiCCP and RF was $100 \%$. Moreover, the sensitivity of both MAGE-I and Anti-CCP was $100 \%$ while that of RF was $85 \%$. 
Table (1): Frequency of synovial MAGE-I mRNA in the studied groups

\begin{tabular}{|c|c|c|c|}
\hline & & & \\
\hline MAGE-1 gene & & Control group & RA group \\
\hline -ve & Count & 10 & 0 \\
\hline -ve & $\%$ & $100 \%$ & $0 \%$ \\
\hline & Count & 0 & 20 \\
\hline$+\mathbf{p e}$ & $\%$ & $0.00 \%$ & $100 \%$ \\
\hline
\end{tabular}

Table (2): Comparison between the studied groups as regards RF and anti-CCP levels

\begin{tabular}{|l|l|l|l|l|}
\hline Data & $\begin{array}{l}\text { Control group } \\
(\mathbf{n}=\mathbf{1 0})\end{array}$ & $\begin{array}{l}\text { RA group } \\
(\mathbf{n}=\mathbf{2 0})\end{array}$ & $\boldsymbol{t}$ & $\mathbf{P}$ \\
\hline RF (IU/mI) & $\mathbf{2 6 . 7 8} \pm \mathbf{1 0 . 0 5}$ & $\mathbf{1 2 3 . 3 1} \pm \mathbf{5 1 . 8 8}$ & $\mathbf{5 . 7 8}$ & $<0.01$ \\
\hline Anti-CCP (IU/ml) & $\mathbf{2 . 7 5} \pm \mathbf{0 . 8 9}$ & $\mathbf{3 5 . 1 7} \pm \mathbf{5 . 4 9}$ & $\mathbf{1 8 . 3 8}$ & $<0.01$ \\
\hline
\end{tabular}

$\mathbf{P}<0.01$ : Significant
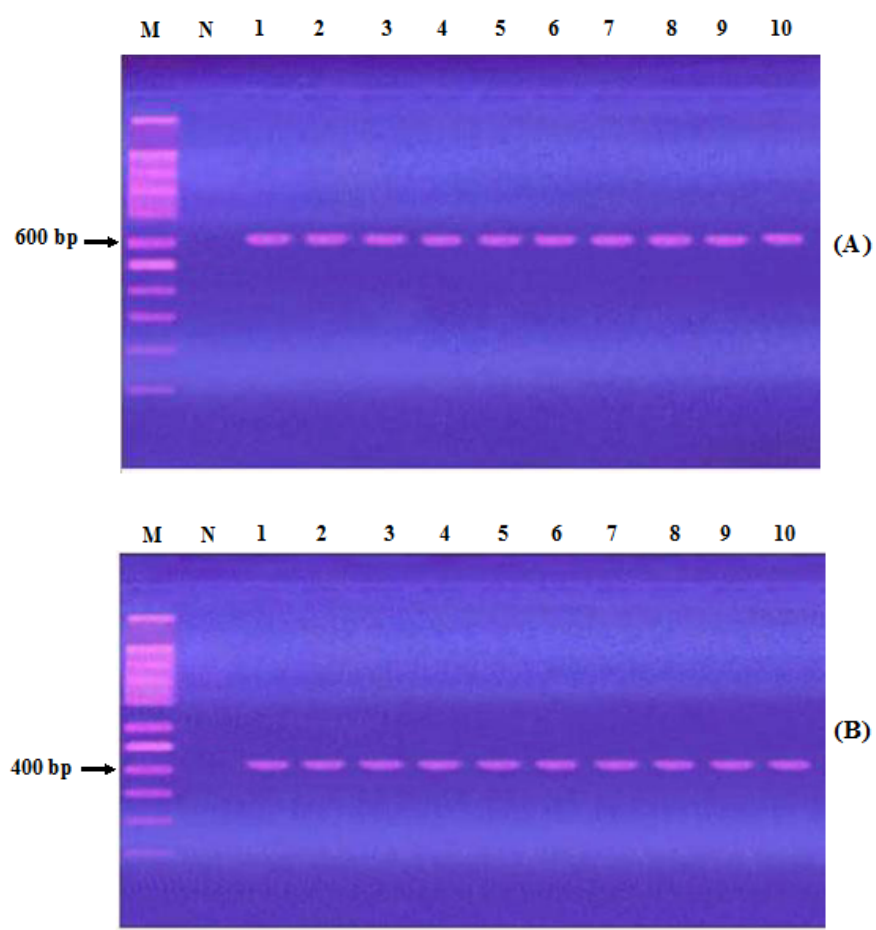

Figure (1): Electrophoresis of the gene expression products in synovial fluid cells samples of rheumatoid patients where (A) is B-actin, (B) is MAGE-1, M: 100bp molecular marker, $\mathrm{N}$ : negative control. Lanes 1-10 show the $613 \mathrm{bp}$ bands of B-actin in (A) and the $421 \mathrm{bp}$ bands of MAGE-1 in (B). 


\section{DICUSSION}

RA is a severe, progressive, systemic inflammatory disease of unknown etiology. The morbidity and mortality it causes are a consequence of local and systemic inflammatory processes that damage cartilage, bone and soft tissue, as well as blood vessels and viscera. Until recently, treatment for RA was limited, and severe joint damage and overall debility were common. Early and aggressive intervention with new and effective biological treatments can alter the course of the disease, and improve the function $^{(\mathbf{1 8})}$, but better molecular markers for diagnosis and prognosis are needed for early diagnosis and treatment of RA patients. Serological testing for RF is complicated by moderate sensitivity and specificity, and high rates of positivity in other chronic inflammatory and infectious diseases $^{(19)}$.

Autoantibodies can give the clinician a more precise indication of the type of underlying disease because they occur specifically in a certain disease. Among the most diseasespecific autoantibodies described are the so-called anti-citrullinated protein/peptide antibodies (ACPA). These antibodies occur specifically in RA and can be measured most conveniently via the anti-CCP antibody test ${ }^{(\mathbf{2 0})}$.

The MAGE-1 gene is a member of the MAGE-A subfamily that comprises at least 12 genes. Their expression in normal adult tissues is restricted to testis only with the exception of MAGE-3 and MAGE-4, which are also expressed in placenta $^{(21)}$. MAGE family proteins were previously thought to be expressed only by certain tumors and presented by HLA Class I, resulting in tumor cell lysis by cytotoxic $\mathrm{T}$ cells.

McCurdy et al. ${ }^{(22)}$ reported that mononuclear cells from inflamed joints of patients with juvenile rheumatoid arthritis (JRA) highly express MAGE-1 mRNA. MAGE-1 expression in JRA suggests an association with autoimmune disease and a possible causal role for MAGE antigen in the chronic inflammation of JRA. This is comparable with our results which revealed that $100 \%$ (20 of 20) of RA patients were found to be positive for MAGE-1 mRNA in the synovial fluid cells by RT-PCR assay.

To explain the role of MAGE in chronic inflammation and autoimmune disease, Catelli et al. ${ }^{(23)}$ hypothesized that an event causing cellular injury results in reactivation of genes that control cell development and proliferation. Genes such as MAGE-A1 that are not normally expressed are induced and presented on the cell surface in the context of the HLA antigen. This activates $T$ cells, and since there is no tolerance to this rarely expressed antigen, an immune response is activated. Then, McCurdy et al. ${ }^{(22)}$ reported that cytokines, following cell activation, are up regulated, providing costimulation for an inflammatory response. With prolonged stimulation, epitope spreading and widespread activation of the immune system may occur. This process is then chronically fueled by the presentation of the MAGE proteins and other self- 
antigens that may be exposed during tissue destruction.

Concerning the expression of MAGE-1 in malignant tumors, several studies have indicated an increased risk of lymphoproliferative malignancies in patients with RA that may well be related to the use of cytotoxic agents or prolonged immunosuppressive therapy ${ }^{(24)}$. Therefore, expression of MAGE-1 in RA may be related to these lymphoproliferative malignancies. Furthermore, the expression of MAGE-1 may be related to that mentioned by Yamanishi and Firestein $^{(25)}$ who stated that, the synovial hyperplasia and pannus formation in patients with arthritis have several features suggestive of malignancy. The pannus formation resembles that of a localized neoplasm. This synovial transformation has been associated with the activation of protooncogenes that regulate the cell cycle and intracellular signaling cascades. In RA, increased expression of protooncogenes, such as early growth response gene-1 (egr-1), c-fos, c-jun, and c-myc, has been implicated in synovial cell proliferation and invasion.

As regard the obtained results of both serum anti-CCP and RF, a significant increase $(\mathrm{P}<0.01)$ of both parameters was detected in the RA group when compared to the control group. This result coïncides with those previously reported by Schellekens et al. ${ }^{(26)}$, Vossenaar and van Venrooij ${ }^{(9)}$, Raza et al. ${ }^{(27)}$, Tedesco et al. ${ }^{(28)}$, Conrad et al. ${ }^{(28)}$, and Wiik et al. ${ }^{(29)}$.
Moreover, our results showed that the specificity of MAGE-I mRNA, anti-CCP antibodies and RF was $100 \%$, and the sensitivity of both MAGE-I m-RNA and Anti-CCP was $100 \%$ while that of RF was $85 \%$. As regard MAGE-I mRNA, its results coincide with those of McCurdy et al. ${ }^{\text {(22) }}$, and the results of anti-CCP and $\mathrm{RF}$ are in parallel with those of Schellekens et al. ${ }^{(26)}$, Van Venrooij, et al. ${ }^{(20)}$ Khosla, et al. ${ }^{(31)}$, Renaudineau, et al. ${ }^{(32)}$ and Samanci, et al. ${ }^{(33)}$.

RF has become the primary laboratory test used in the diagnosis of $\mathrm{RA}$. RF is found in the sera of up to $85 \%$ of patients with $\mathrm{RA}^{(33)}$; however, it is also found in many other diseases, including Sjögren's syndrome, systemic lupus erythematosus, and mixed connective tissue disease ${ }^{(34)}$. In addition, RF is found in the sera of five percent to ten percent of apparently healthy individuals ${ }^{(31)}$. The presence of RF in so many other conditions decreases the diagnostic specificity of the RF test, resulting in the search for a more specific test for the diagnosis of RA.

The anti-CCP antibodies assay was found to have a high sensitivity comparable to that of the RF test; however, the specificity proved to be superior $^{(20)}$. Schellekens et $\mathbf{a l}^{(20)}$ concluded that, anti-CCP antibodies are very specific for RA. Anti-CCP antibodies meet all the requirements of a good serological marker for RA. Their high specificity and prognostic value make them a valuable diagnostic tool. Due to its high specificity for RA, anti-CCP antibodies can be used to differentiate RA from other forms of arthritis that 
may be confused with RA because they can be erosive and RF positive. In RF seronegative patients, AntiCCP antibodies can be helpful in confirming the diagnosis of RA, because approximately $40 \%$ of RF negative RA patients are positive for anti-CCP antibodies ${ }^{(\mathbf{9})}$.

Comprehensive studies found that the specificity of anti-CCP ranges from 88.9 - $100 \%$, depending upon the diseases included in each study. Anti-CCP autoantibodies are also found in diseases other than RA, although at a lower frequency than $\mathrm{RF}^{(34)}$.

The specificity of anti-CCP antibodies for RA is clarified by Hill et al. ${ }^{(35)}$ who reported that, the HLADR4 allele is strongly associated with RA. The presence of HLA-DR4 was associated with the presence of antiCCP antibodies in the RA. It has been proposed that the interaction between citrullinated self peptides and the SE carried by HLA-DR alleles may result in the induction of anti-CCP antibodies in patients with adult-onset RA.

The anti-CCP production starts very early, in many cases even before clinical symptoms of RA have appeared. In early RA, more than half of the patients are anti-CCP antibodies positive ${ }^{(30)}$. Furthermore, Raza et al. ${ }^{(27)}$ reported that, by using anti-CCP antibodies and RF, it is now possible to predict with a very high specificity which patients with very early synovitis (within the first 3 months of symptoms) will develop RA. Consequently these patients can be targeted with anti-inflammatory therapies as soon as they present to clinic.
Conclusively, the obtained results of testing the expression of MAGE-1 transcript in synovial fluid showed $100 \%$ positivity encouraging its utilization as a biochemical marker for the diagnosis of RA. Also, MAGE-1 transcript evaluation should be used as an adjunct marker with anti-CCP to help early diagnosis of RA.

\section{Recommendations:}

Further studies are required to detect whether the level of MAGE expression is correlated with the progress of the RA to estimate its clinical utility as a prognostic marker and monitor the response to the therapy. Furthermore, we need a greater understanding of the expression of MAGE genes in RA because it may elucidate a pivotal step in the development of the chronic immune response and autoimmune disease in general.

\section{REFERENCES}

1. Pratt, A.G.; Isaacs, J.D. and Mattey, D.L. (2009): Mattey:Current concepts in the pathogenesis of early rheumatoid arthritis. Best Pract. Res. Clin. Rheumatol.; 23(1): 37.

2. Smolen, J.S.; Aletaha, D.; Grisar, J.; Redlich, K.; Steiner, G. and Wagner, O. (2008): The need for prognosticators in rheumatoid arthritis. Biological and clinical markers: where are we now? Arthritis Res. Ther., 10(3): 208.

3. van Venrooij, W.J. and Zendman, A.J. (2008): AntiCCP2 Antibodies: An Overview and Perspective of the Diagnostic 
Abilities of this Serological Marker for Early Rheumatoid Arthritis. Clinic. Rev. Allerg. Immunol., 34: 36.

4. Nicole, L.A.; Carolyn, B.E. and Margot, H. (2008): Rheumatoid factor and anti-CCP autoantibodies in rheumatoid arthritis: A Review. Clin Lab Sci; 21(1): 15

5. Nienhuis, R.L. and Mandema, E. (1964): A New Serum Factor in Patients with Rheumatoid Arthritis; the Antiperinuclear Factor. Ann. Rheum. Dis., 23: 302.

6. Young, B.J.; Mallya, R.K.; Leslie, R.D.; Clark, C.J. and Hamblin, T.J. (1979): Antikeratin antibodies in rheumatoid arthritis. Br. Med. J., 2: 97.

7. Sebbag, M.; Simon, M.; Vincent, C.; Masson-Bessière, C.; Girbal- Neuhauser, E.; Durieux, J.J. and Serre, G. (1995): The antiperinuclear factor and the so-called antikeratin antibodies are the same rheumatoid arthritis-specific autoantibodies. J. Clin. Invest., 95: 2672.

8. Girbal-Neuhauser, E.; Durieux, J.J.; Arnaud, M.; Dalbon. P.; Sebbag, M.; Vincent, C.; Simon, M.; Senshu, T.; Masson-Bessière, C.; JolivetReynaud, C.; Jolivet, M. and Serre, G. (1999): The epitopes targeted by the rheumatoid arthritis-associated antifilaggrin autoantibodies are posttranslationally generated on various sites of filaggrin by deimination of arginine residues. J. Immunol., 162: 585.
9. Vossenaar, E.R. and van Venrooij, W.J. (2004): AntiCCP antibodies, a highly specific marker for (early) rheumatoid arthritis. Clin. Applied Immunol. Rev., 4: 239.

10. Niewold, T.B.; Harrison, M.J. and Paget, S.A. (2007): AntiCCP antibody testing as a diagnostic and prognostic tool in rheumatoid arthritis. QJM., 100: 193.

11. Xiao, J. and Chen, H-S. (2004): Biological functions of melanoma-associated antigens. World J. Gastroenterol., 10(13): 1849.

12. Barker, P.A. and Salehi, A. (2002): The MAGE proteins: emerging roles in cell cycle progression, apoptosis, and neurogenetic disease. J. Neurosci. Res., 67(6): 705.

13. McCurdy, D.K.; Tai, L.Q.; Nguyen, J.; Wang, Z.; Yang, H.M.; Udar, N.; Naiem, F.; Concannon, P. and Gatti, R.A. (1998): MAGE Xp-2: A member of the MAGE gene family isolated from an expression library using systemic lupus erythematosus sera. Mol. Gen. Metabol., 63 (1): 3.

14. Dabadghao, S; Misra, R; Naveed, $M$ and Aggarwal $A$. (1996): IgM rheumatoid factor estimation by ELISA in seronegative rheumatoid arthritis before and after IgM fractionation: does seronegative RA exist? Rheumatol Int.; 15(5): 189.

15. Quinn, M. A.; Gough, A. K. S.; Green, M. J.; Devlin, J.; Hensor, E. M. A.; Greenstein, 
A.; Fraser, A. and Emery, P. (2005): Anti-CCP antibodies measured at disease onset help identify seronegative rheumatoid arthritis and predict radiological and functional outcome. Rheumatology; 45: 478.

16. Noonan, K.E. and Roninson, I.B. (1988): mRNA phenotyping by enzymatic amplification of randomly primed cDNA. Nucleic Acids Res., Nov 1988; 16: 10366.

17. Mou, D.C.; Cai, S.L.; Peng, J.R.; Wang, Y.; Chen, H.S.; Pang, X.W, Leng, X.S. and Chen, W.F. (2002): Evaluation of MAGE-1 and MAGE-3 as tumour-specific markers to detect blood dissemination of hepatocellular carcinoma cells. Br. J. cancer, 86(1): 110.

18. De Vries-Bouwstra, J.K.; Dijkmans, B.A. and Breedveld, F.C. (2005): Biologics in early rheumatoid arthritis. Rheum. Dis. Clin. North Am., 31: 745.

19. Dörner, T.; Egerer, K.; Feist, E. and Burmester, G.R. (2004): Rheumatoid factor revisited. Curr. Opin. Rheumatol.; 16: 246.

20. Van Venrooij, W.J.; Hazes, J.M. and Visser, H. (2002): Anticitrullinated protein/ peptide antibody and its role in the diagnosis and prognosis of early rheumatoid arthritis. Neth J Med; 60(10): 383.

21. De Plaen, E.; De Backer, O.; Arnaud, D.; Bonjean, B.; Chomez, P.; Martelange, V.; Avner, P.; Baldacci, P.; Babinet, C.; Hwang, S.Y.; Knowles, B. and Boon, $\mathbf{T}$. (1999): A new family of mouse genes homologous to the human
MAGE genes. Genomics, 55(2): 176.

22. McCurdy, D.K.; Tai, L-Q.; Imfeld, K.L.; Schwartz, M.; Zaldivar, F. and Berman, M.A. (2002): Expression of Melanoma Antigen Gene by Cells from Inflamed Joints in Juvenile Rheumatoid Arthritis. J. rheumatol.; 29: 2219.

23. Catelli, C.; Rivoltini, L.; Andreola, G.; Carrabba, M.; Renkvist, N. and Parmiani, G. (2000): T-cell recognition of melanoma-associated antigens. J. Cell. Physiol., 182: 323.

24. Wolfe, F. and Michaud $K$. (2004): Lymphoma in rheumatoid arthritis: the effect of methotrexate and anti-tumor necrosis factor therapy in 18,572 patients. Arthritis Rheum., 50: 1740.

25. Yamanishi, Y. and Firestein, G.S. (2001): Pathogenesis of rheumatoid arthritis; the role of synoviocytes. Rheum. Dis. Clin. North Am., 27: 355.

26. Schellekens, G.A.; Visser, H.; de Jong, B.A.; van den Hoogen, F.H.; Hazes, J.M.; Breedveld, F.C. and van Venrooij, W.J. (2000): The diagnostic properties of rheumatoid arthritis antibodies recognizing a cyclic citrullinated peptide. Arthritis Rheum., 43: 155.

27. Raza, K.; Buckley, C.E.; Salmon, M. and Buckley, C.D (2006): Treating very early rheumatoid arthritis. Best Pract. Res. Clin. Rheumatol., 20(5): 849 .

28. Tedesco, A.; D'Agostino, D.; Soriente, I.; Amato, P.; Piccoli, 
R. and Sabatini, P. (2009): A new strategy for the early diagnosis of rheumatoid arthritis: A combined approach. Autoimmun. Rev., 8: 233.

29. Conrad, K.; Roggenbuck, D.; Reinhold, D. and Dörner, T. (2010): Profiling of rheumatoid arthritis associated autoantibodies. Autoimmun. Rev., 9: 431.

30. Wiik, A.S.; van Venrooij, W.J. and Pruijn, G.J. (2010): All you wanted to know about anti-CCP but were afraid to ask. Autoimmun. Rev., 10(2): 90.

31. Khosla, P.; Shankar, S. and Duggal, L. (2004): Anti CCP antibodies in rheumatoid arthritis. J Indian Rheumatol Assoc; 12: 143.

32. Renaudineau, Y.; Jamin, C.; Saraux, A. and Youinou, $P$. (2005): Rheumatoid factor on a daily basis. Autoimmunity; 38(1): 11.
33. Samanci N, Ozdem S, Akbas H, and Mutlu, D.; Gultekin, M.; Arman, M. and Donmez, L. (2005): Diagnostic value and clinical significance of anti-CCP in patients with advanced rheumatoid arthritis. J Nat Med Assoc; 97(8): 1120.

34. Riedemann, J.P.; Muñoz, S. and Kavanaugh, A. (2005): The use of second generation antiCCP antibody (anti-CCP2) testing in rheumatoid arthritis - a systematic review. Clin Exp Rheumatol; 23(Suppl 39): S69.

35. Hill, J.A.; Southwood, S.; Sette, A.; Jevnikar, A.M.; Bell, D.A. and Cairns, E. (2003): Cutting edge: the conversion of arginine to citrulline allows for a highaffinity peptide interaction with the rheumatoid arthritis associated HLA-DRB $1 * 0401$ MHC class II molecule. J. Immunol., 171: 538. 


\title{
القياس النوعى للحمض النووى الريبوزى الرسول لماج-1 فى السائل الزلالى المئ كاتجاه جديد فى تثخيص الرئيان المفصلي الريول في
}

\author{
إيمان عبل القادر عبل السلام، إبراهيم المغاوري،

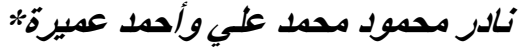

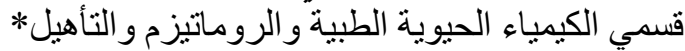 \\ كلية الطب، جامعة الزقازيق الرومانيق
}

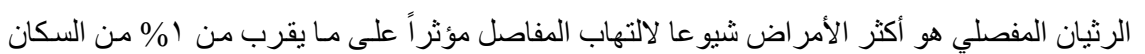

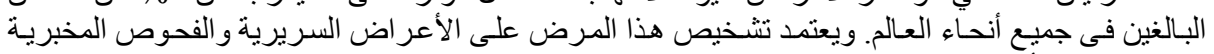

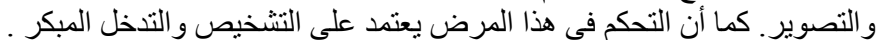

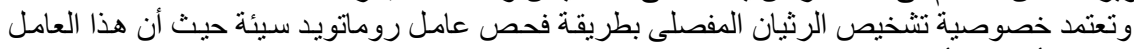

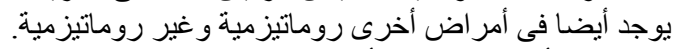

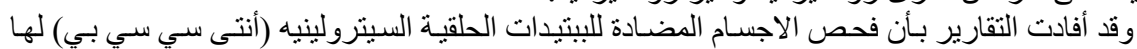

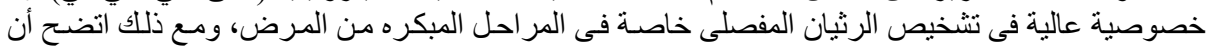

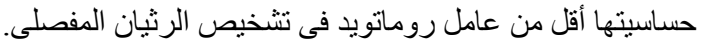

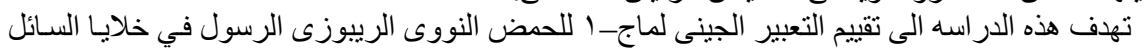

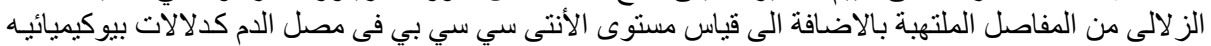

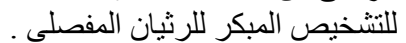

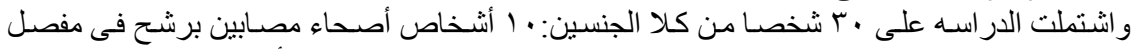

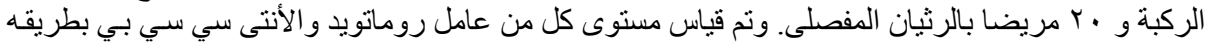

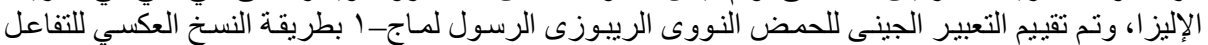

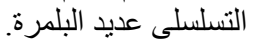

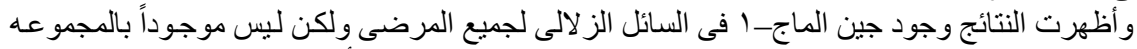

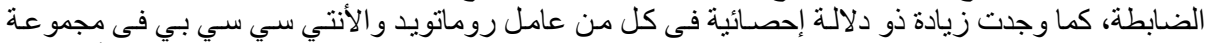

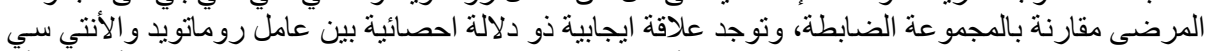

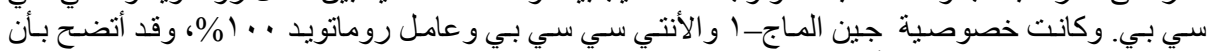

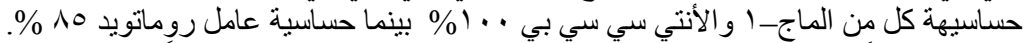

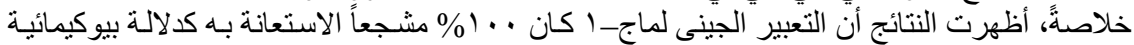

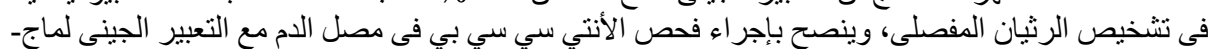

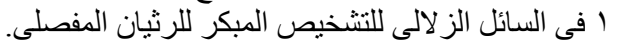

